\title{
Thermoelectric and Magnetic Nanowires
}

\author{
Yu-Biao Liu and Shao-Min Zhou \\ Key Lab for Special Functional Materials of Ministry of Education, \\ Henan University, Kaifeng, \\ China
}

\section{Introduction}

Approximately 90 per cent of the world's power is generated by heat engines that use fossil fuel combustion as a heat source and typically operate at 30-40 percent efficiency, such that roughly 15 terawatts of heat is lost to the environment (Hochbaum et al., 2008). Thermoelectric modules could potentially convert part of this low-grade waste heat to electricity (Lecher, 1905). In addition, it can also be used for thermoelectric cooler instead of Freon (succedaneum for Freon) and will not cause any environmental pollution (Thompson, 1932). According to solid state physics, semiconductor, semimetal, and some alloys are ideal thermoelectric material, and the efficiency of the thermoelectric materials depends on the thermoelectric figure of merit $Z T\left(Z T=T S^{2} \sigma / \kappa\right)$ : a function of the absolute temperature $(T)$, of the Seebeck coefficient ( $S$, or thermoelectric power), and of the electrical $(\sigma)$ and thermal conductivities $(\kappa)$ (Bucherer, 1900). Unfortunately, over the past ten decades it has been challenging to increase ZT for bulk thermoelectric materials, which are difficult to be used widely due to the low thermoelectric efficiency (Bell, 2008). Since the 1990s, Q1D nanostructures, particularly for NWs, have made great progress, in which many conventional materials have been made into the structural and morphology of NWs and then the unique properties appear (Masuda et al.,1997; Li et al., 1998; Ling et al., 1999; Gudiksen \& Lieber, 2000; Wu et al., 2002; Gao et al., 2003; Lee et al., 2006; Zhou et al., 2008; Zhou et al., 2009; Zhou et al., 2010; Zhou et al., 2011). Under the one-dimensional, with improvement of the system of states near the Fermi energy density, the Seebeck coefficient of the system is improved. Simultaneously, with scaling down to a certain size, phonon scattering is enhanced without affecting the transmission of electronic. So thermoelectric NW shows a quite higher thermoelectric figure of merit ZT and the interest in thermoelectric NWs has been stimulated greatly by the discovery of its excellent thermoelectric properties (Ying, J. \& Heremans,1998). In order to produce a variety of thermoelectric NWs, some new methods such as solvothermal and electro-deposition have been employed (Jin et al., 2004; Li, 2003; Li, 2006). Here we review the research status of NWs of thermoelectric materials, which include elements, alloys, and the development of thermoelectric super-lattice NWs will be also introduced. NW materials show excellent characteristics, which exhibit different property compared to bulk materials.

In addition, as for magnetic NW section, it is found that magnetic NWs have a significant magnetic anisotropy and exhibit a large coercivity and a large remanence ratio when magnetization direction along NWs. Because of these unique low-dimensional properties, 
magnetic NWs with straight shape are the best candidate to be applied for magnetic storage media with high density domain. In the past period time, a variety of magnetic NWs have been synthesized and characterized by nanotechnology, and here we also review the fabrication of the NW arrays of ferromagnetic metal, alloy, and heterogeneous ferromagnetic-nonmagnetic alloy. In the two section review, besides the method of nuclear track etching and thermal reduction, we highlight the common method of electrodeposition inside the anodic aluminum oxide template, with predomination of fast growth, simple device, and simplified operation, which has been employed for the synthesis of NW arrays. Several physical methods, especially microscopic techniques such as scanning electron microscopy (SEM), transmission electron microscopy (TEM), scanning tunneling microscopy (STM) and atomic force microscopy (AFM) are commonly used to characterize NWs. We present a comprehensive and up-to-date review of the thermoelectric and magnetic NWs wherein we discuss their synthesis along with their properties and potential applications.

\section{Synthesis strategy}

\subsection{Thermoelectric nanowires}

\subsubsection{Vapor phase synthesis}

Gas phase reaction is a kind method for wildly used to synthesis. Due to the special property of low-dimensional nanostructure, it is extensively used for producing NWs. The idea of synthesis is based on the vapor-liquid-solid (VLS) process, and the schematic diagram of the synthesis is shown in Fig 1 (Gudiksen \& Lieber, 2000; Yang et al., 2002; Wagner \& Ellis, 1964; Wu \& Yang, 2001; Givargizov, 1975; Gao et al., 2003; Lee et al., 2006).

(a)
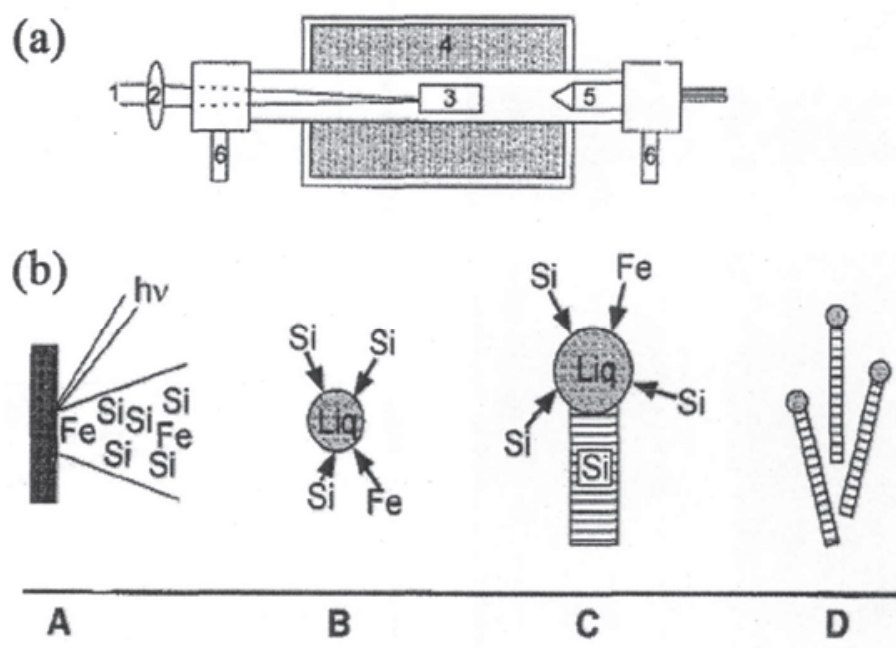

B

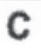

D

Fig. 1. Vapor-liquid-solid (VLS) process.

Under an inert gas, putting substrate in the appropriate place of temperature and leading to a certain amount of organic metal or the reaction gas source from against target by pulsed 
laser semiconductor material. As the example of synthetic silicon NWs (Gudiksen \& Lieber, 2000), in a temperature, the vapor of Si-Fe can form into the droplet mucleation undercooling. As more gas through, content of silicon in the droplet will be more and more and tends to saturation, and $\mathrm{Si}$, exist in the droplets, is precipitated to a crystalline NWs (Wagner \& Ellis, 1964). Combined with the technology of repeated precipitation or pulse deposition, the method based on vapor-liquid-solid mechanism has been used to produce super-lattice NWs. Yang's research group has successfully synthesized Single-Crystalline $\mathrm{Si} / \mathrm{SiGe}$ Super-lattice NWs by using the hybrid pulse laser ablation/chemical vapor deposition (PLA-CVD) method (Yang et al., 2002). Fig 2 shows the single-crystalline Si/SiGe super-lattice NWs growth apparatus. Si wafer coated with a thin layer of Au was put inside a quartz furnace tube as substrate.

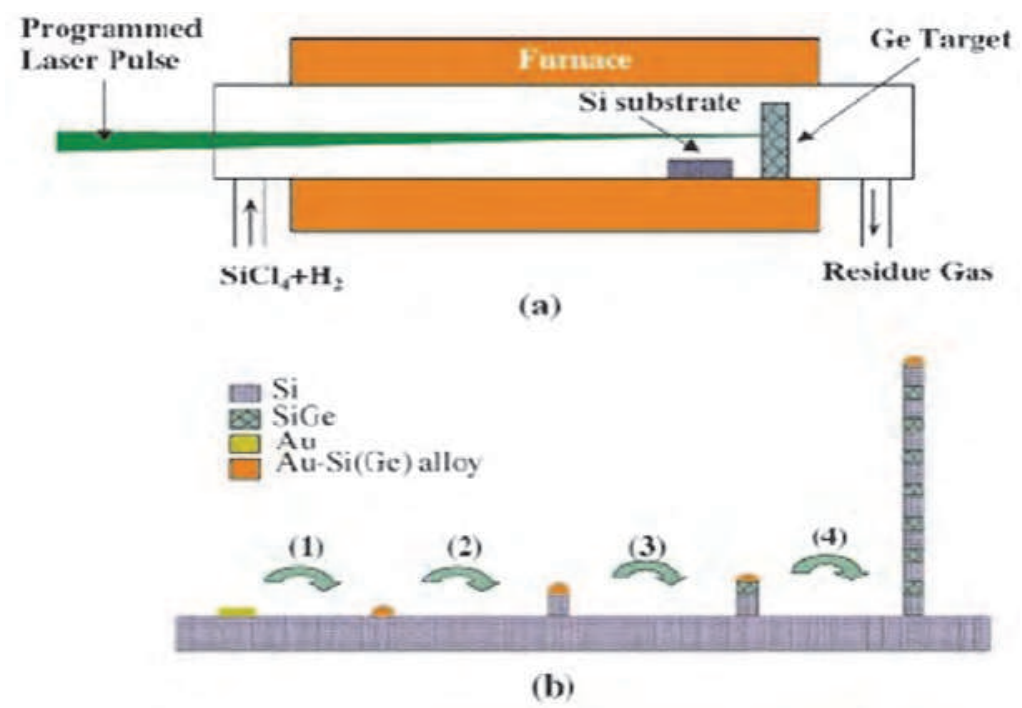

Fig. 2. Schematic illustration of the experimental setup (a) and vapor-liquid-solid sequential NW growth mechanism (b).

A gas mixture of $\mathrm{H}_{2}$ and $\mathrm{SiCl}_{4}$ was continuously introduced into the reaction tube. NW growth is based on the well-known vapor-liquid-solid (VLS) mechanism (Figure 2) with Au as solvent at high temperature (Wagner \& Ellis, 1964; Wu \& Yang, 2001; Givargizov, 1975). At a suitable temperature, an Au thin film forms a liquid alloy with $\mathrm{Si}$ and spontaneously breaks up into nanometer sized droplets (Figure 2 (1)). Si species continuously deposit into $\mathrm{Au}-\mathrm{Si}$ alloy droplets where the Si NW growth is initiated upon super-saturation (Figure 2 (2)). During this growth process, if the laser is turned on, Ge vapor will be generated and both Ge and Si species will be deposited into the alloy droplets. The SiGe alloy then precipitates from the solid/liquid interface (Figure 2 (3)). By periodically turning the laser on and off (this sequence can be readily programmed), $\mathrm{Si} / \mathrm{SiGe}$ super-lattice is formed on every individual NW (Figure 2 (4)) in a block-by-block fashion. Very recently, our research group (Zhou et al., 2011) reports on $\beta-\mathrm{Zn}_{4} \mathrm{Sb}_{3}$ nanocantilevers and their thermoelectric properties. As shown in Fig. 3, the as-fabricated products have a cantilever morphology and a high ZT value 

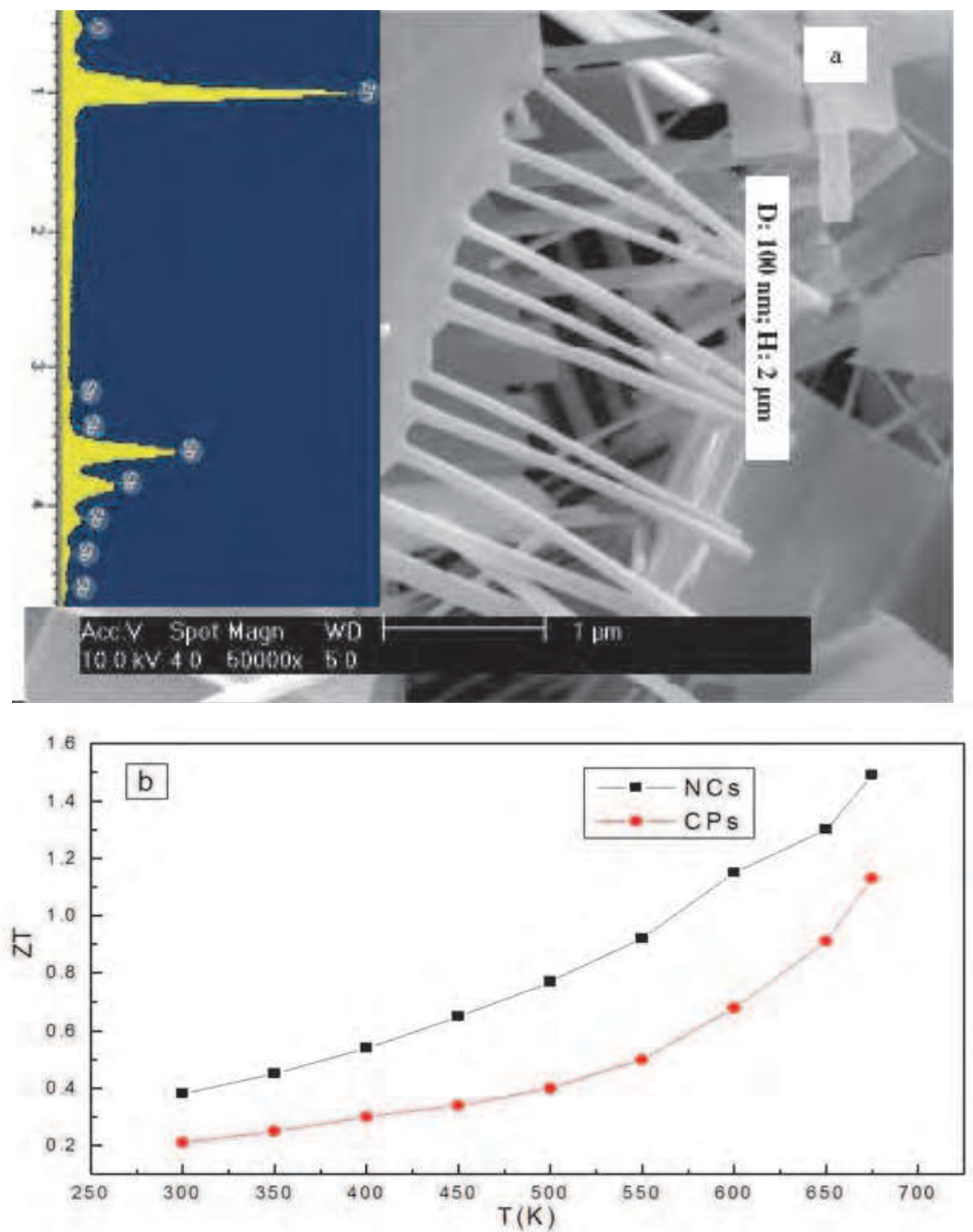

Fig. 3. A typical SEM image of $\beta-Z n 4 S b 3$ nanocantilever (a) and thermoelectric figure of merit ZT (T) (b) of the as-produced $\beta$-Zn4Sb3 nanocantilever (NCs, black) and $\beta$-Zn4Sb3 conventional powders (CPs, red) as a function of temperature

\subsubsection{Liquid phase synthesis}

As a simple and convenient method, liquid phase reaction method is widely used to fabricate a tailored material by controlling the liquid environment of the crystal growth process with out complex equipment. Gao et al. (Gao et al., 2003 ) have fabricated Bi NWs with $20 \sim 30 \mathrm{~nm}$ in diameter and $0.2 \sim 0.3 \mathrm{~mm}$ in length by solvothermal method. Although this method is simple, but mostly the structure of the synthesized NWs is very few, and this method is rarely employed for the synthesis of thermoelectric NW materials (Lee et al., 2006; Masuda et al., 1997; Li et al., 1998; Ling et al., 1999). 


\subsubsection{Electrochemical template synthesis}

Electrochemical template method has been successfully used to the synthesis of thermoelectric NWs with various materials. In this technique, the template serves as a scaffold against which other materials with similar morphologies are synthesized That is, the in situ generated material is shaped into a nanostructure with morphology complementary to that of the template. The nanoscale channels are filled using the electrochemical method. Until now, the most common templates are nanoscale channels within porous alumina and polycarbonate membranes. Unlike the polymer membranes with the broader and uneven distribution of pore size, fabricated by track etching, anodic alumina membranes (AAMs) containing a hexagonally packed 2D array of cylindrical pores with a uniform size are prepared using anodization of aluminum foils in an acidic medium. Porous alumina template pore size is controlled by adjusting the polarization voltage. However, when the voltage is too large, aluminum oxide template is easy to burn due to the lack of distribution of heat (Lee et al., 2006). Different acidic electrolytes have their own optimum aperture. It is found that sulfuric acid electrolyte is adapt to synthesize Alumina template with less than $50 \mathrm{~nm}$ in diameter (Masuda et al., 1997), oxalic acid electrolyte is adapt to synthesize Alumina template with $50 \sim 100 \mathrm{~nm}$ in diameter (Li et al., 1998), and phosphoric acid electrolyte is adapt to synthesize alumina template with $100 \sim 300 \mathrm{~nm}$ in diameter (Li et al., 1998) as shown in Fig 4.

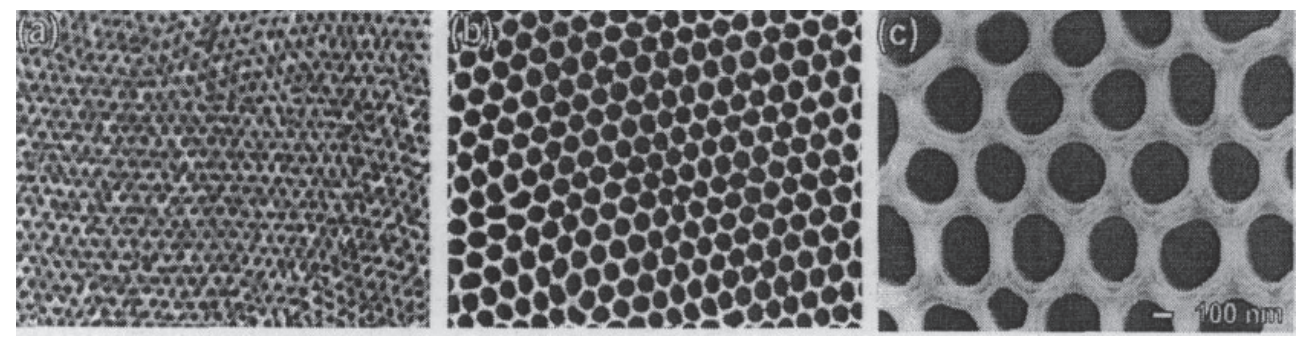

Fig. 4. Alumina templates of various apertures.

High-quality aluminum oxide template can be achieved by the method of reoxidation (Ling et al., 1999). The method of electro-deposition in anodic alumina membranes has been proved to be very effective and convenient to synthesize thermoelectric NWs. They first synthesized the NW arrays of the $\mathrm{Bi}_{2} \mathrm{Te}_{3}, \mathrm{Bi}-\mathrm{Sb}-\mathrm{Te}$, and Bi-Te-Se thermoelectric material at room temperature (Prieto et al., 2001; Prieto et al., 2003; Martin-Gonzalez et al., 2003). To get uniform growth NW arrays of the various apertures, they made a depth work on the growth rate of NWs at the different temperatures. $\mathrm{Li}$ et al. modulate the growth of the $\mathrm{Bi}_{2} \mathrm{Te}_{3}$ NWs with the different orientations by the method of pulse electrochemical deposition (Li et al., 2006), and the NW's diameter can also be modulated by controlling the cycle of the pulse plating and the concentration of the plating solution. In addition, the pulse plating template, based on the principle of that different ions have different potential, can be used to synthesis various themoelectrice super-lattice NWs, and the junctions with different lengths can be achieved by different plating time. So we can conclude that electrochemical template method provides a very reliable and controllable pathway for the synthesis of the thermoelectric NWs. 


\subsection{Magnetic nanowires}

There are various methods for the preparation of magnetic NWs such as physical methods and chemical methods. However, the template method is widely used to fabricate magnetic NWs because of its unique advantages. The main application template include porous anodic aluminum oxide template (AAO), porous silicon templates, and track etched polymer membranes template.

\subsubsection{Porous anodic alumina template}

By the method of the electro deposition, the amount of metal deposition can be controlled by controlling the deposition time, and the aspect ratios of the NWs can be precisely controlled. Due to the way of driving metal ions, it can be divided into alternating current, direct current deposition, and pulsed power deposition. For the AC deposition, it is no need to separate the template form the $\mathrm{Al}$ matrix after the formation of ordered nanoporous, and various magnetic NW arrays can be fabricated by controlling the current, voltage, frequency and time parameters, after decreasing the thickness of the dense alumina film. As early as 1991, Mawlawi et al. (Aimawlawi et al., 1991) synthesized polycrystalline Fe NW arrays with diameter of $22 \mathrm{~nm}$ by ac electro deposition in porous anodic alumina template. While the operation process of ac electro deposition is simple and feasible, it can only be used to assemble single metal or alloys. The methods of DC or pulse electro-deposition can also be used to synthesize magnetic NW arrays. Alumina template is first stripped from the $\mathrm{Al}$ matrix, through-hole, and then the back of the template is coated metal film as a cathode by sputtering or vacuum coating. By controlling the voltage, current, temperature, and time conditions to prepare magnetic NWs, then the template is removed to obtain corresponding NWs. While it is a more complicated operation, various forms of magnetic nanophase materials such as multilayer magnetic NWs. Sol-gel method is a new fiber preparation technology, and can also be used to prepare magnetic NW arrays. It is that after a solution, Sol-gel and cure, Organometallic compounds or inorganic salts become oxides or other solid compounds by heat treatment. This method does not require special equipment, and the NW length can be controlled by impregnation times (Qin, 2006). For example, Otten et al (Otten et al., 2002) prepared NWs of cobalt ferrite using sol-gel method under different annealing speeds. Sol-gel template method has been used to fabricate highly ordered NW arrays of iron oxide (Liu et al., 2005). A large area of iron oxide NWs can be prepared by solgel template method, which suggests that it is easy to control conditions, reproducible, the process simple, and low cost. Chemical-deposition is known as electroless deposition or chemical plating. In order to prepare NWs, the metal is deposited into the channel or surface of the template by chemical reduction. Using $\mathrm{Co}_{2}(\mathrm{CO})_{8}$ as precursor, Aranda et al (Aranda \& Garcia, 2002) synthesize Co NWs in the AAO template and the polycarbonate template by chemical-deposition method.

\subsubsection{Track etched polymer membranes template}

Track etching polymer template preparation methods are as follows: Firstly, polymer film such as $6 \sim 10 \mu \mathrm{m}$ thick polycarbonate is bombard by fission fragments, and then the membrane damage is rusted into the nano-pore by chemical method. Polymer template has cylindrical nanopore with the pore size of $10 \sim 200 \mathrm{~nm}$ and the pore density of $10^{9} \mathrm{~cm}^{-2}$. While the pore canal of polymer template is not regular than that of anodic alumina template, polymer template, which has good flexibility, can maintain a long time in highly acidic conditions. So the applications of polymer template are more widely. 


\subsubsection{SBA-16 film}

SBA-16 film, which is progressive development after the successful development of molecular sieve, is a highly ordered three-dimensional body-centered cubic film with a high degree of order of the pore structure and a average pore diameter of $8 \sim 9 \mathrm{~nm}$.

\section{Thermoelectric nanowires}

\subsection{Bi}

Bismuth, as a semimetal with a very small band gap, provides a very attractive model system for studying low-dimensional physical phenomena due to its highly anisotropic Fermi surface, low carrier densities, small carrier effective masses, and long carrier mean free path(Dresselhaus et al., 2003; Zhang et al., 2000). The experiment results indicate that a semimetal-semiconductor transition in bismuth NWs when the wire diameter is decreased to a certain value (about $50 \mathrm{~nm}$ ), which carried out by a novel vacuum melting and pressure injection technique (Zhang et al., 1998). The results of Fig. 5 indicate that these bismuth NWs undergo a semimetal-to-semiconductor transition due to two-dimensional quantum confinement effects.

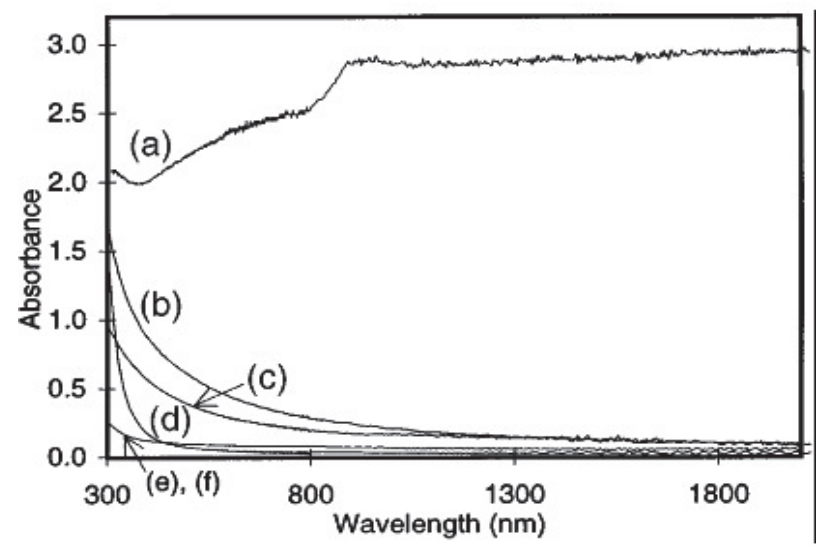

Fig. 5. The room-temperature optical absorption spectra of the Bi NW/anodic alumina composite films with average wire diameters of (a) $56 \mathrm{~nm}$, (b) $23 \mathrm{~nm}$, and (c) $13 \mathrm{~nm}$, and the corresponding unfilled anodic alumina templates (d), (e), and (f).

Considerable effort has been devoted to synthesis Bi NWs and Bi NW arrays with diameters of 5-200 nm have been fabricated by liquid-phase pressure injection (Zhang et al., 1999), solution-phase process, vapor-phase deposition (Heremans et al., 2000), or electrochemical deposition (Liu et al., 1998; Piraux et al., 1999), until now, and various transport measurements have been performed to study classical and quantum finite-size effects.

\section{$3.2 \mathrm{Si}$}

Researches of thermoelectric properties of silicon NWs, during all kinds of thermoelectric NWs, have made the most outstanding progress. Since the researcher discovered that there is large difference in mean free path lengths between electrons and phonons at room 
temperature: $110 \mathrm{~nm}$ for electrons in highly doped samples and $300 \mathrm{~nm}$ for phonons in highly doped silicon materials (Ju et al., 1999). Consequently, incorporating structures with critical dimensions below $300 \mathrm{~nm}$ in Si should reduce the thermal conductivity without significantly affecting Seebeck coefficient because of scattering on phonon transmission. The first report of the thermal conductivities of individual single crystalline Si NWs was by Yang's research group ( $\mathrm{Li}$ et al., 2003; Wu et al., 2002), who synthesized SiNWs by the vapor-liquid-solid method, in which Au clusters were used as solvent at high temperature. The $\mathrm{Si}$ and $\mathrm{Au}$ formed a liquid alloy and when the alloy became supersaturated with $\mathrm{Si}, \mathrm{Si}$ NWs grew by precipitation at the liquid-solid interface. The Si NWs, which are synthesized by that method, are single crystalline. Thermal conductivity measurements of individual and $115 \mathrm{~nm}$ diam single crystalline Si NWs carried out using a micro-fabricated suspended device over a temperature range of $20-320 \mathrm{~K}$ as shown in Fig 6.

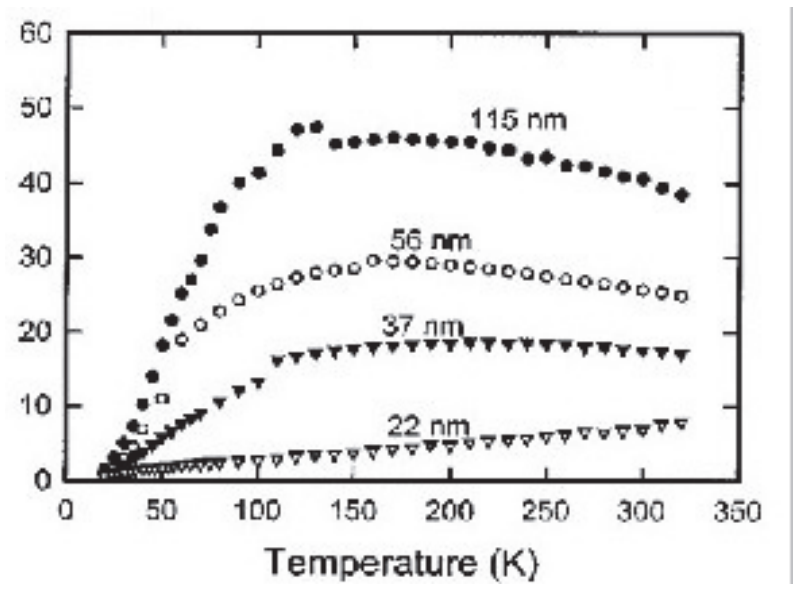

Fig. 6. Measured thermal conductivity of different diameter Si NWs. The number beside each curve denotes the corresponding wire diameter.

The thermal conductivity observed is more than two orders of magnitude lower than the bulk value. The strong diameter dependence of thermal conductivity in NWs is ascribed to the increased phonon-boundary scattering and possible phonon spectrum modification. Thermoelectric performance of rough silicon NWs had been made a detailed study by Hochbaum et al. (Hochbaum et al., 2008), who synthesized Wafer-scale arrays of Si NWs by an aqueous electroless etching (EE) method (Venkatasubramanian et al., 2001; Touloukian et al., 1970; Weber \& Gmelin,1991). NWs synthesized by this approach are vertically aligned and consistent throughout batches, and across large areas up to wafer-scale. Figure 7a (Venkatasubramanian et al., 2001) is a cross-sectional scanning electron microscope (SEM) image of one such array, and the inset shows a one-inch-square NW array. The NWs varied from 20 to $300 \mathrm{~nm}$ in diameter with an average diameter of approximately $100 \mathrm{~nm}$, as measured from TEM micrographs (Fig 7b). The NWs are single crystalline, as shown by the selected area electron diffraction pattern (top inset) and high-resolution TEM image of the Si lattice of an EE NW in Fig 7c. In contrast to the smooth surfaces of typical vapour-liquidsolid (VLS)-grown, gold-catalyzed Si NWs (Fig 7d), these of the EE Si NWs are much rougher. 

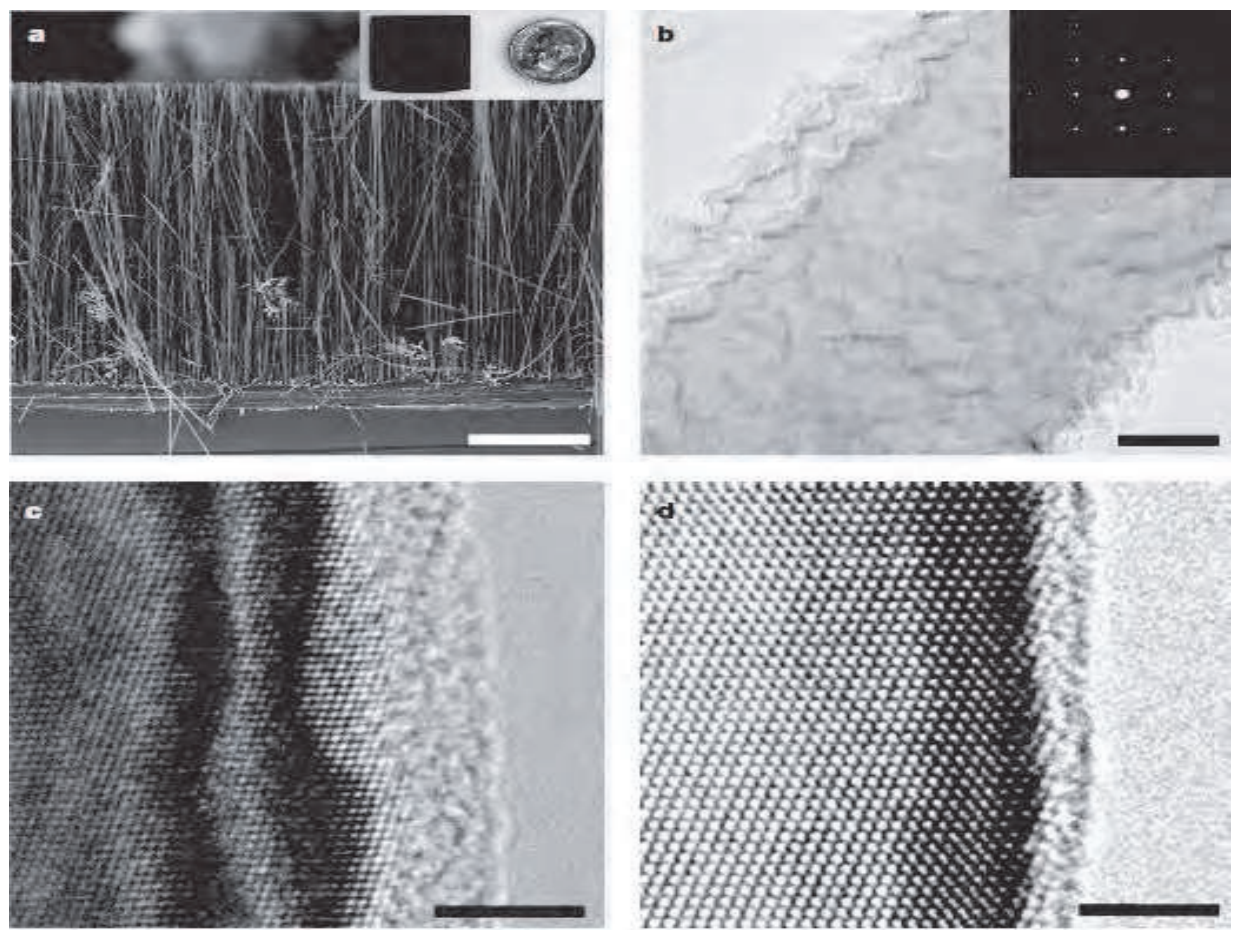

Fig. 7. (a) Cross-sectional SEM of an EE Si NW array; (b)Bright-field TEM image of a segment of an EE Si NW; (c) High-resolution(HR)TEM image of an EE Si NW; (d) HRTEM of a VLS-grown Si NW.

By the test of thermal conductivity of individual NWs, it has been shown that the magnitude of the k of EE Si NWs is five- to eight fold lower than VLS Si NWs of comparable diameters, which indicate that the roughness at the NW surface behaves like secondary scattering phases for $\mathrm{k}$ can be reduced by introducing scattering at additional length scales beyond the NW diameter. They founded that the peak $k$ of the EE NWs is shifted to a much higher temperature than that of VLS NWs, and both are significantly higher than that of bulk Si, which peaks at around $25 \mathrm{~K}$.

\section{3 $\mathrm{Bi}_{1-\mathrm{x}} \mathrm{Sb}_{\mathrm{x}}$}

Bulk $\mathrm{Bi}_{1-x} \mathrm{Sb}_{\mathrm{x}}$ alloys are among the best $\mathrm{n}$-type low-temperature TE materials $(20<\mathrm{T}<220 \mathrm{~K})$, and the properties of the alloy change dramatically with composition. For alloys with $12 \%$ $\mathrm{Sb}$, the dimensionless figure of merit, ZT, is 0.88 at $80 \mathrm{~K}$. These properties of the alloy change dramatically with composition and the Bi-rich alloys have large TE efficiencies. New experimental and theoretical results suggest that the thermoelectric efficiencies of quantumconfined materials are enhanced compared with those of bulk materials, so it has been a resurgence of interest in the fabrication of $\mathrm{Bi}_{1-x} \mathrm{Sb}_{\mathrm{x}} \mathrm{NWs}$. The method of electro-deposition from dimethyl sulfoxide (DMSO) had been used for fabrication of dense arrays of crystalline $\mathrm{Bi}_{1-\mathrm{x}} \mathrm{Sb}_{\mathrm{x}}(0 \leq \mathrm{x} \leq 0.15)$ NWs with $40-\mathrm{nm}$ diameters by Prieto (Prieto, 2003). A representative Xray diffraction pattern of the filled template is shown in Fig 8 . 


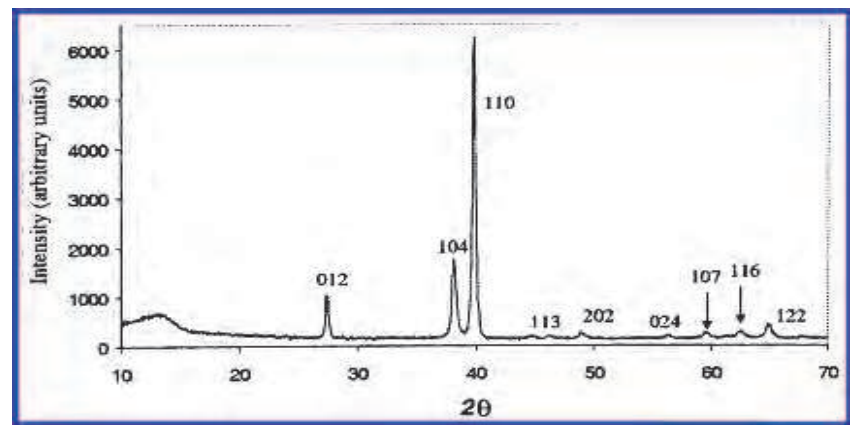

Fig. 8. XRD of 40-nm Bi-Sb NWs after the electrode layer has been removed mechanically.

The high intensity of the 110 peak shows that the wires are oriented and that the preferred wire axis is $\langle 110\rangle$, which is different from the orientation obtained by pressure injection with the normal to <012> parallel to the wire axis (Chien et al., 1998; Searson et al., 1998). They concluded that by tuning the solution concentrations and controlling the growth rate by controlling the potential, the composition, crystallinity, and morphology of the NWs can be tuned.

\subsection{Bi-Te}

During the past fifty years, the bismuth telluride $\left(\mathrm{Bi}_{\mathrm{x}} \mathrm{Te}_{1-\mathrm{x}}\right)$ based compounds have been a focus of extensive research because of their best thermoelectric performance near the room temperature and bismuth telluride alloys have remained the bulk materials with the highest ZT close to unity at $\mathrm{T}=300 \mathrm{~K}$ (Mahan et al., 1997). In recent years, with the research that the properties of $\mathrm{Bi}_{\mathrm{x}} \mathrm{Te}_{1-\mathrm{x}}$ alloys have a strong dependence on the $\mathrm{Bi}$ concentration and the discovery of evident improvement of the figure of merit in the quantum-confined systems compared to bulk materials, $\mathrm{Bi}_{\mathrm{x}} \mathrm{Te}_{1-\mathrm{x}} \mathrm{NWs}$ have been prepared by an electrochemical deposition method widely (Jin et al., 2004). Large scale and highly ordered thermoelectric $\mathrm{Bi}_{\mathrm{x}} \mathrm{Te}_{1-\mathrm{x}}(0.4 \leq \mathrm{x} \leq 0.7) \mathrm{NW}$ arrays were successfully fabricated by electrochemical deposition in AAM template (Wang et al., 2007). The structure of the NWs was characterized by X-ray diffraction and selected-area electron diffraction (SAED). Field emission scanning electron microscopy (FE-SEM) and transmission electron microscopy (TEM) results show that the NWs are smooth and uniform with the diameters of about $50 \mathrm{~nm}$ and lengths up to tens of micrometers. Energy dispersive spectroscopy (EDS) was used to check the exact stoichiometry of as-prepared samples. The results reveal that the atomic ratio between $\mathrm{Bi}$ and Te can be modulated effectively by controlling the concentration of the electrolyte solution. The synthesis of high quality $\mathrm{Bi}_{\mathrm{x}} \mathrm{Te}_{1-\mathrm{x}} \mathrm{NWs}$ with controllable $\mathrm{x}$ is significant for optimizing the thermoelectric performance. Shi et al. designed an experiment to measure the thermoelectric properties of individual $\mathrm{Bi}_{\mathrm{x}} \mathrm{Te}_{1-\mathrm{x}} \mathrm{NWs}$ prepared by an electrochemical deposition method, which suggested that the high ZT can be potentially obtained with an optimized atomic ratio (Zhou et al., 2005). A typical SEM image of a $\mathrm{Bi}_{\mathrm{x}} \mathrm{Te}_{1-\mathrm{x}} \mathrm{NW}$ trapped on the two suspended membranes of the measurement device as shown in Fig 8. Because of limited synthesis of $\mathrm{Bi}_{x} \mathrm{Te}_{1-x} \mathrm{NWs}$ with different compositions, the thermoelectric performance of the $\mathrm{Bi}_{x} \mathrm{Te}_{1-x} \mathrm{NWs}$ has not been systematically investigated. The focus of future research of $\mathrm{Bi}_{x} \mathrm{Te}_{1-x} \mathrm{NWs}$ is to make the dependence of the optimal conditions and thermal on properties composition clear. 


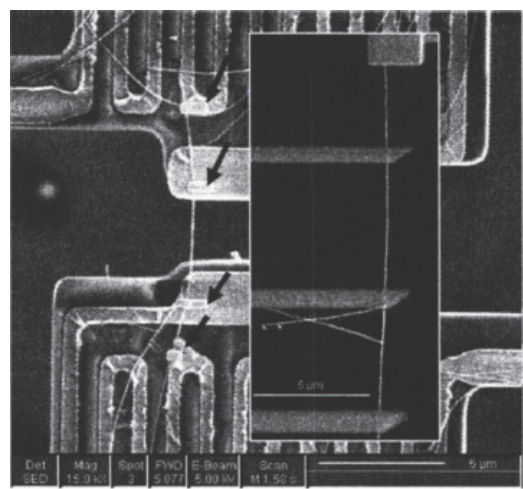

Fig. 9. SEM of a $\mathrm{Bi}_{x} \mathrm{Te}_{1-\mathrm{x}} \mathrm{NW}$ trapped on the two suspended membranes of the measurement device.

\section{5 $\mathrm{Bi}_{2} \mathrm{Te}_{3}$}

Bismuth telluride are among the best known thermoelectric materials for the modern commercial application, which possess notable properties such as high anisotropic multivalley Fermi surface, small value of the thermal conductivity, and optimal value of the carrier concentration at room temperature (RT). The thermoelectric figure of merit ZT of the $\mathrm{Bi}_{2} \mathrm{Te}_{3}$ super-lattices was reported to have the value of 2.4 while the maximum $\mathrm{ZT}$ for the bulk bismuth telluride material is less than 1 at room temperature. Due to stronger spatial confinement, the bismuth tellurides NWs are expected to be better than the quantum well super-lattices. So the work of depth research of bismuth telluride NWs has been carried out. Until now, the method of synthesis of $\mathrm{Bi}_{2} \mathrm{Te}_{3} \mathrm{NWs}$ is few, but the method of template based on AAO is widely used and fairly mature for fabricating $\mathrm{Bi}_{2} \mathrm{Te}_{3} \mathrm{NWs}$. The first report of the fabrication of Ordered $\mathrm{Bi}_{2} \mathrm{Te}_{3}$ NW Arrays by electro-deposition was by Prieto et al.( Prieto et al., 2001), who had demonstrated the fabrication of dense, continuous $\mathrm{Bi}_{2} \mathrm{Te}_{3}$ wires with uniform diameters of $40 \mathrm{~nm}$ by direct electro-deposition into an alumina template. The deposited wires are highly textured in the [110] direction as shown in Fig 10.

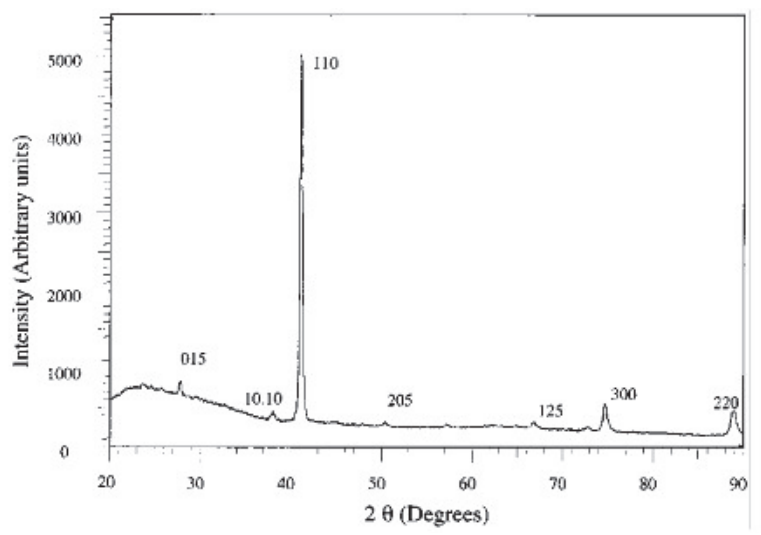

Fig. 10. Representative X-ray diffraction pattern of a filled $40 \mathrm{~nm}$ template. 
Due to the good characteristics of the template for NW array fabrication, Sander et al. had chosen electro-deposition, and produced arrays of bismuth telluride $\left(\mathrm{Bi}_{2} \mathrm{Te}_{3}\right) \mathrm{NWs}$ with diameters of $\sim 25, \sim 50$, and $\sim 75 \mathrm{~nm}$ successfully using electrochemical deposition into porous anodic alumina templates. SEM confirms that the NW arrays are dense with a narrow distribution of NW diameters as shown in Fig 11.

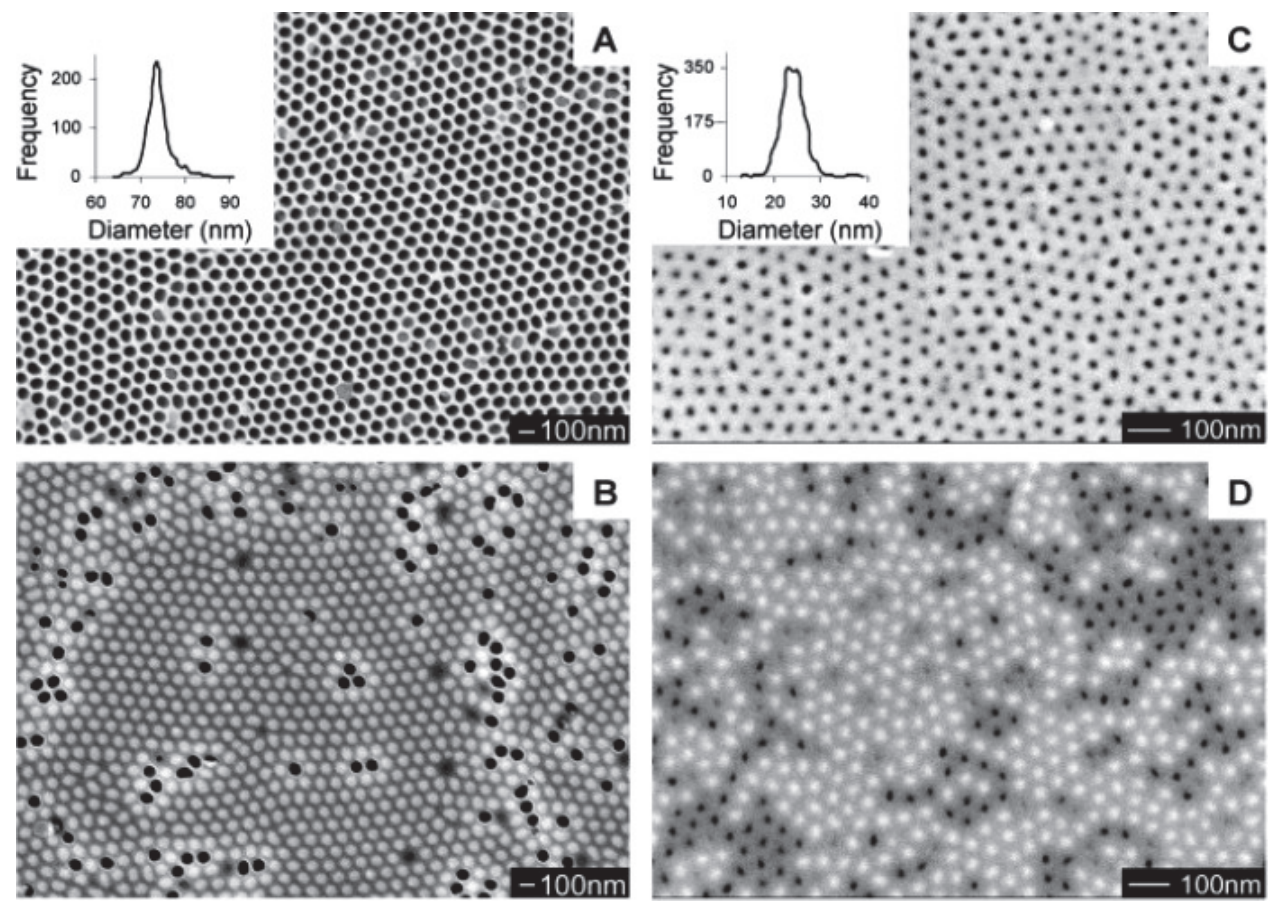

Fig. 11. (a) Empty template (b) array composite with average wire diameter of $75 \mathrm{~nm}$ (c) empty template (d) array composite with average wire diameter of $25 \mathrm{~nm}$. The insets show pore diameter distribution for large (a) and small (c) diameter templates. Dark areas in these images are due to empty pores, whereas bright spots are due to the $\mathrm{Bi}_{2} \mathrm{Te}_{3} \mathrm{NWs}$.

The latest theoretical studies show that electric field effect (EFE) is a powerful tool controlling the electrical properties of low dimensional structures. Bejenari et al. theoretically studied how the electric field effect can modify thermoelectric properties of intrinsic, n-type and p-type bismuth telluride NWs with the growth direction <110> (Bejenari et al., 2010). After comprehensive analysis of various theories, the results of their calculations indicate that the external perpendicular electric field can increase the Seebeck coefficient of the bismuth telluride NWs with thicknesses of 7-15 nm by nearly a factor of 2 and enhance ZT by an order of magnitude. At room temperature, ZT can reach a value as high as 3.4 under the action of the external perpendicular electric field for realistic widths of the NWs. The obtained results may open up a way for a drastic enhancement of the thermoelectric figure of merit in a wide temperature range. The work of controlling the growth of bismuth telluride NWs and analysing the factors of oriented growth of bismuth telluride NW arrays have been carried out by the electrochemical deposition of the material 
in the nanoporous of anodized alumina membranes (Miyazaki \& Kajitani,2001). The work and results of those researches lay the first stone for the measurement and optimization of bismuth telluride thermoelectric NWs.

\subsection{Super-lattice nanowires}

Theoretical calculations predict that further enhancement of the thermoelectric figure of merit can be achieved in super-lattice NWs (zero-dimensional) (Lin \& Dresselhaus, 2003) rather than conventional NWs (1D) or super-lattice thin-films (2D), and thermoelectric super-lattice NWs are promising systems for the thermoelectric applications for this structure is believed to be better in reducing phonohen transport and keeping high electron mobility (Hicks \& Dresselhaus, 1993; Lin \& Dresselhaus, 2003). Li et al. (Li, 2003) designed a experiment to measure the thermal conductivity of 58 and $83 \mathrm{~nm}$ diameter Si/SiGe single crystalline super-lattice NWs, which were synthesized by a hybrid pulsed laser ablation/chemical vapor deposition process based on vapor-liquid-solid mechanism. Figure 12a shows a TEM image of a Si/SiGe NW, and a SEM image of an $83 \mathrm{~nm}$ diameter Si/SiGe super-lattice NW bridging the two suspended pads is shown in Fig 12b.
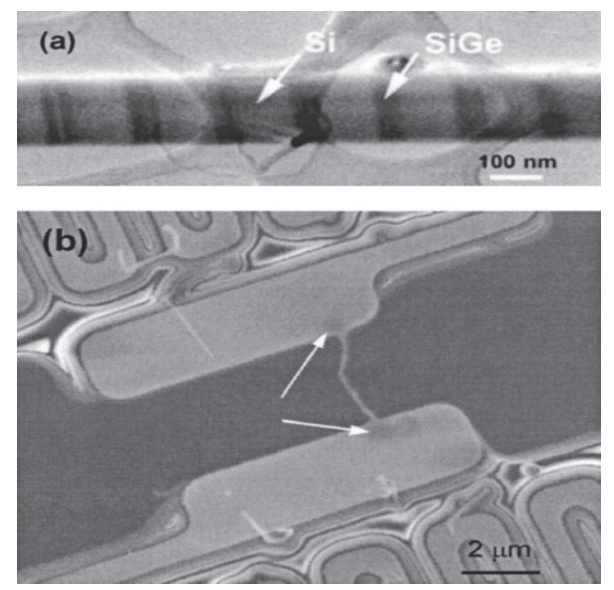

Fig. 12. (a) A transmission electron micrograph of a Si/SiGe super-lattice NW. (b) A scanning electron micrograph of an $83 \mathrm{~nm} \mathrm{Si} / \mathrm{SiGe}$ super-lattice NW bridging the two suspended heater pads. The arrows point to the carbon deposits.

The observed thermal conductivity shows similar temperature dependence as that of twodimensional $\mathrm{Si} / \mathrm{SiGe}$ super-lattice films. Comparison with the thermal conductivity data of intrinsic Si NWs suggests that alloy scattering of phonons in the Si-Ge segments is the dominant scattering mechanism in these super-lattice NWs. Yang et al. (Wu et al., 2002) had developed a hybrid pulsed laser ablation/chemical vapor deposition (PLA-CVD) process for the synthesis of semiconductor NWs with longitudinal ordered heterostructures, and have been successfully synthesized Single-crystalline NWs with longitudinal Si/SiGe superlattice structure. Xue et al. reported a method for preparing super-lattice NW arrays in a single ethanol bath by using a pulsed electro-deposition technique (Xue et al., 2005). Here $\mathrm{Bi} / \mathrm{Sb}$ super-lattice NW arrays had been fabricated by using this method and also four kinds of modulated structures of $\mathrm{Bi} / \mathrm{Sb}$ super-lattice NWs with different periods had been 
synthesized. This simple and efficient method can be expected to be used in other systems which can be electrodeposited. Heterostructured ZnSe-ZnTe quantum wires having axial heterojunctions are grown by the solution-liquid-solid (SLS) mechanism (Dong et al., 2007), and they found that the nature of the axial or radial heterostructure obtained is strongly influenced by the growth sequence and related synthetic conditions. Yoo et al (Yoo et al., 2007). electrodeposited $\mathrm{Bi}_{2} \mathrm{Te}_{3} /\left(\mathrm{Bi}_{0.3} \mathrm{Sb}_{0.7}\right)_{2} \mathrm{Te}_{3}$ super-lattice $\mathrm{NWs}$ by using a templatedirected method, where the composition and length of each segment was precisely controlled by adjusting deposition potentials and times Figure 13 shows SEM and TEM images of the NWs after removal of the polycarbonate template.

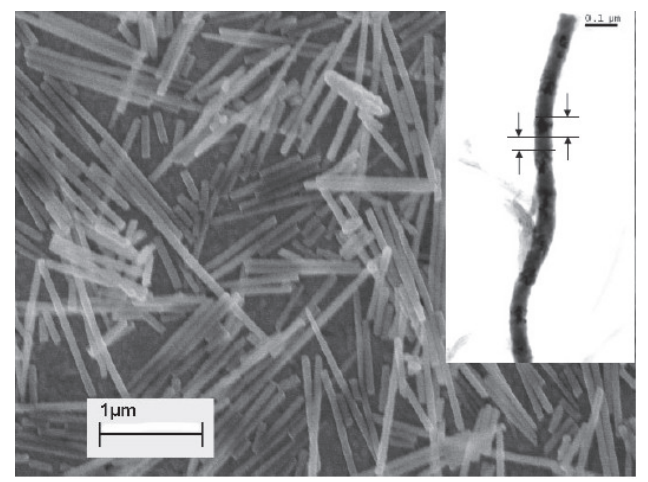

Fig. 13. Microstructure of the super-lattice BiSbTe NWs after removal of the polycarbonate template, the inset image was obtained by transmission electron microscopy (TEM).

The compositional modulation within the NWs was examined by electron dispersive X-ray spectroscopy (EDS) with the line-scanning method, where the intensity of the characteristic $\mathrm{Bi} \mathrm{La}$ and $\mathrm{Sb}$ Ka peaks is plotted as a function of distance as shown in Fig 14.

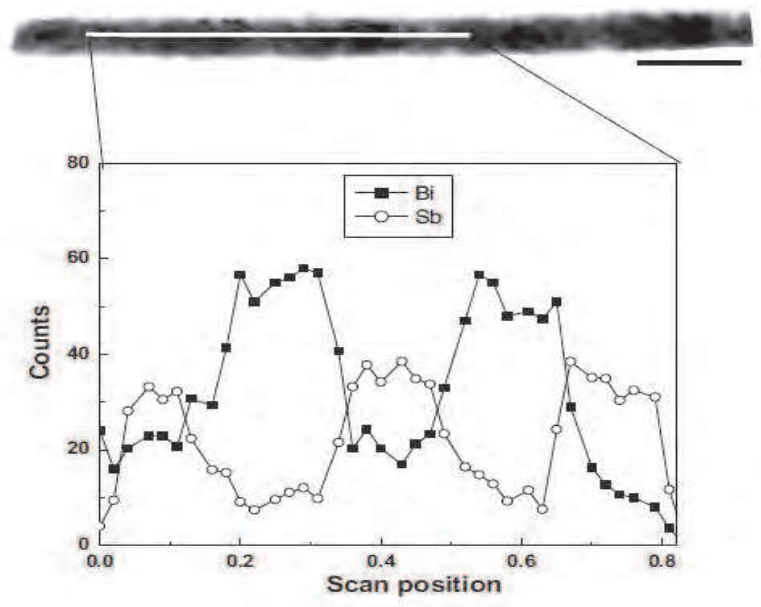

Fig. 14. Energy dispersive X-ray spectrometry (EDS) line scan, showing compositional oscillations of $\mathrm{Sb}$ and $\mathrm{Bi}$ in a BiSbTe super-lattice NWs. 
Although there are several methods on the synthesis of thermoelectric super-lattice NWs, the test of thermoelectric properties is very lack, because the current thermoelectric superlattice NW materials, which can be fabricated successfully, are also very small, and the corresponding methods and parameters are very complex.

\section{Magnetic nanowires}

\subsection{Element}

\subsubsection{Fe}

Magnetic properties of Fe NWs had been studied by a number of groups, and Fe NWs had been fabricated in typical sizes range from 10 to $100 \mathrm{~nm}$ in diameter and from 0.1 and $1 \mu \mathrm{m}$ in length. There is a depth investigation in the behaviour of the coercivity of the Fe NWs. Figure 14 shows hysteresis loops for wires having a diameter of $9 \mathrm{~nm}$ and a length of $1 \mu \mathrm{m}$; the field is applied parallel and perpendicular to the wire axis. When the field is parallel to the wire axis (perpendicular to the film plane), the coercivity is about 2300 Oe (remanence ratio $\mathrm{Mr} / \mathrm{Ms}=0.96$ ), whereas the coercivity measured perpendicular to the wire axis (in the film plane) is about 300 Oe (remanence ratio 0.055 ).

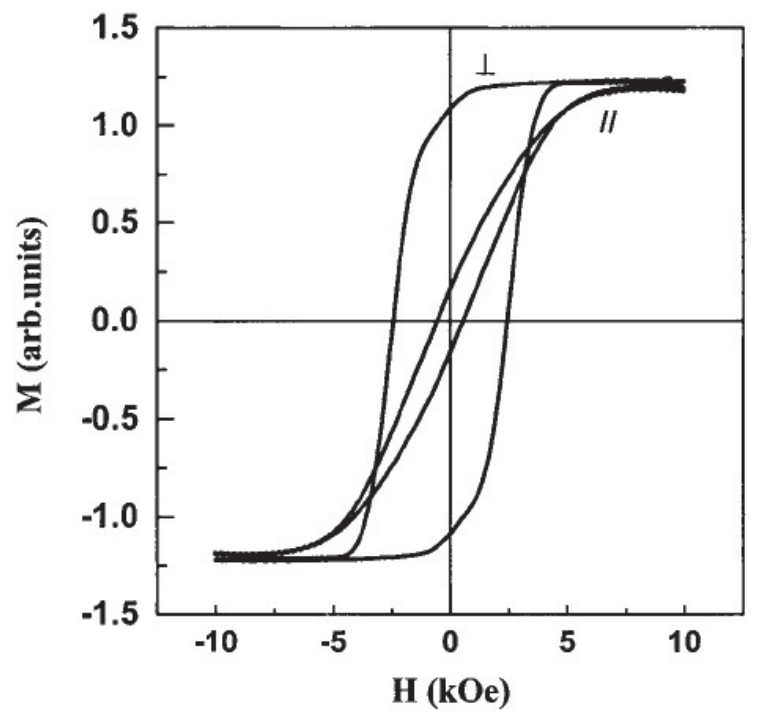

Fig. 15. Typical magnetic hysteresis loops for Fe NW arrays.

This indicates that the wires possess uniaxial anisotropy with the easy axis along the wire axis. The perpendicular anisotropy arises mainly from the shape anisotropy of the wires. The coercivity measured along the wire axis is $2100-2700$ Oe for Fe (Menon et al., 2000; Huysmans \& Lodder, 1988). Sugawara et al. fabricated Fe NWs by soaking the anodized film in phosphoric acid, and the diameter of Fe NWs is then controlled by the soaking time: varying from 9 to $19 \mathrm{~nm}$ for pore-widening times from 0 to 30 minutes (Sugawara et al., 1998). The variation of the coercivity as a function of pore diameter is shown in figure 16(a), and they find that $\mathrm{Hc}$ increases with increasing diameter until a maximum is reached at about $13 \mathrm{~nm}$. The largest coercivity measured by Menon et al. is 2640 Oe for a diameter of 13 
nm. Moskovits et al (Li et al., 1998; Li \& Metzger, 1997) reported maximum values of 2220 Oe and 2240 Oe, respectively, both obtained for sulphuric-acid-anodized templates. So we can see that it is possible to control the magnetic properties of the wires by controlling the fabrication parameters for the dependence of Hc on the wire diameter. Some Fe samples were annealed in an attempt to cause grain growth and thus to influence the coercivity. Fig 16(a) shows that annealing at $100{ }^{\circ} \mathrm{C}, 200{ }^{\circ} \mathrm{C}$ and $300{ }^{\circ} \mathrm{C}$ enhances the coercivity for all NWs. However, annealing at even higher temperatures $\left(400{ }^{\circ} \mathrm{C}\right)$ causes the coercivity drop to about 50 Oe, suggesting that the nanostructures are destroyed or oxidized. The oxidation is probably caused by the ions involved in the deposition process (Prieto et al., 2001). The value of the low-temperature coercivity $(T=5 \mathrm{~K})$ is higher than that of the room temperature coercivity with the same diameter of Fe NWs as shown in Fig 16(b). The coercivity also depends on the aspect ratio, $\mathrm{lw} / \mathrm{dw}$ (wire length divided by wire diameter). $\mathrm{Li}$ et al. found that the coercivity of Fe NW increases gradually with increasing aspect ratio, but increases very little when the aspect ratio is larger than 10:1 ( $\mathrm{Li}$ et al., 1998; $\mathrm{Li} \&$ Metzger, 1997).

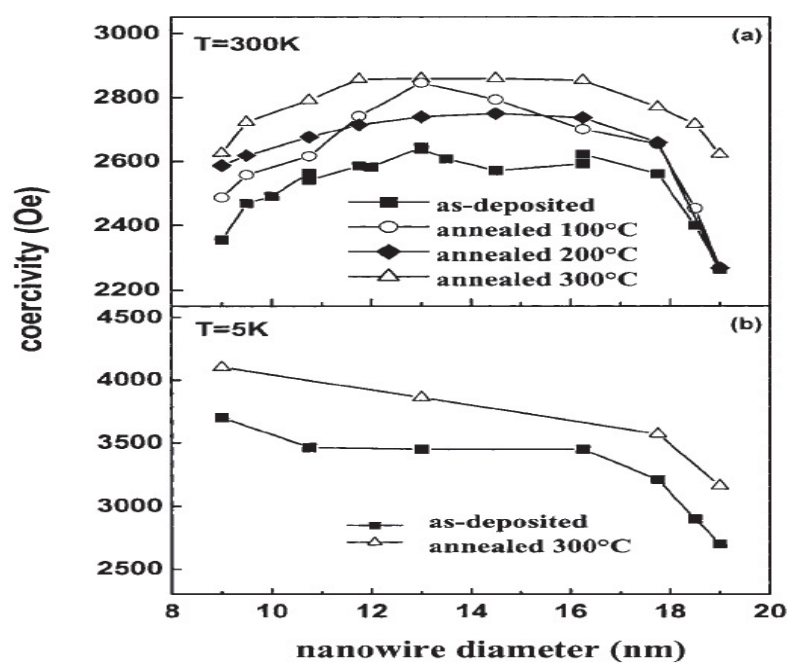

Fig. 16. (a) Hc as a function of NW diameter for as-deposited and annealed samples, and (b) diameter dependence at $5 \mathrm{~K}$ and $300 \mathrm{~K}$.

Almawlawi et al. studied the coercivity of Fe NWs deposited into oxalic-acid-anodized alumites as a function of deposition time, pore-widening time and anodizing voltage. They found that the coercivity depends strongly on the aspect ratio and only weakly on the pore density (anodizing voltage) Hc decreases as the widening time increases.

\subsection{Co}

Typical hysteresis loops for Co NWs in an anodic alumina template are similar to those of Fe NWs as shown in figure 15, and Zeng $\mathrm{H}$ et al. found that the coercivity measured in the perpendicular direction is as high as $2.6 \mathrm{kOe}$ whereas the remanence ratio exceeds 0.9 emu/g (Zeng et al., 2000). Figure 17 shows coercivity and thermal activation volume as a function of the NW diameter (dw) and length (lw). 

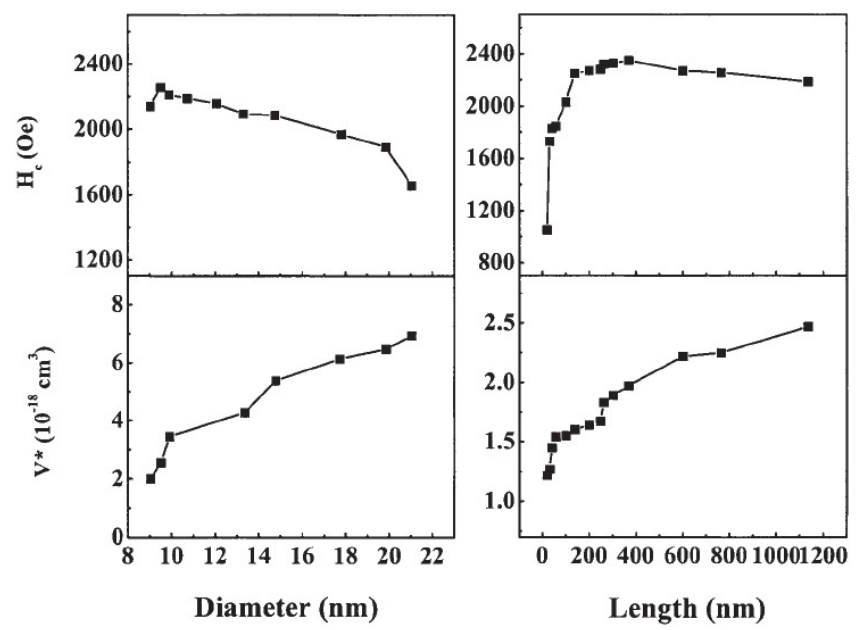

Fig. 17. Dependence of coercivity Hc and thermal activation volume $\mathrm{V}^{*}$ of Co NWs on wirediameter $\mathrm{dw}$ and length $\mathrm{l}_{\mathrm{w}}$.

The thermal activation volume is used to investigate the energy barriers responsible for the magnetization reversal mechanism. $\mathrm{V}^{*}$ has been determined by exploiting the sweep-rate dependence of coercivity and magnetic viscosity measurements. It is shown that with increasing NW length, Hc increases steeply until a constant value of about 2300 Oe is approached, at a length of about $200 \mathrm{~nm}$. V*increases first rapidly but then gradually with $\mathrm{lw}$, but it is generally much smaller than the physical wire volumes. The effect of the applied magnetic field for the growth of Co NWs had been investigated by Chaure et al (Chaure et al., 2005). They demonstrated that the magnetic anisotropy axis and crystallographic texture can be controlled to some extent by applying an external field during electro-deposition of cobalt in a nanoporous alumina membrane. In Co NWs, electrodeposited in anodic alumina, Stijkers et al. observed a reversal magnetization that strongly depends on wire length $(0.5 \leq \mathrm{L}$ $(\mu \mathrm{m}) \leq 40)$. This reversal magnetization is explained as competition between the demagnetizing fields and the dipolar interactions among wires. In order to check the general validity of these results, the method of electro-deposition in polycarbonate membrane pores had been used to produce arrays of cobalt NWs, with diameters in the range 100-400 nm and lengths of $\mathrm{L}<6 \mathrm{~mm}$ by Kazadi Mukenga Bantua et al (Kazadi Mukenga Bantua et al., 2001). It can be concluded, from the measurements of hysteresis loops at room temperature, in the range of template pore diameters studied $(100-200-400 \mathrm{~nm})$, that the shortest wires have an easy axis of magnetization parallel to the axes of the wires, and the longest wires present a crossover towards perpendicular directions. This has been explained by a simple magnetostatic model, which corresponds to competition between the dipolar interactions, demagnetizing field, and the Co magnetocrystalline anisotropy. Very recently, our group (Zhou et al., 2011) reported wet chemical synthesis and magnetic properties of single crystal Co nanochains with surface amorphous passivation Co layers.

\section{$4.3 \mathrm{Ni}$}

Magnetic properties of nickel NWs had been investigated by several groups in recent years. In order to investigate the dependence of magnetic properties of nickel NWs on electro- 
deposition process parameters (especially the $\mathrm{pH}$ and the temperature) and the electrical properties as a function of applied magnetic field in the presence of high frequency excitations. Rahman et al (Rahman et al., 2003) fabricated Nickel NWs through the pores of NCA of 200 and $20 \mathrm{~nm}$ nominal pore size using galvanostatic electro-deposition technique by applying a constant current density of $10 \mathrm{mAcm}^{-2}$. They made a study on the growth of NWs on the electrochemical cell parameters such as bath temperature, $\mathrm{pH}$ and time. It is found that bath temperature influences the preferred orientation of electrodeposited NWs regardless of $\mathrm{pH}$ of the electrolyte. By various kinds of property measurement, it is shown that the coercivity has a strong dependence on the $\mathrm{pH}$ of the electrolyte, and impedance change in the presence DC magnetic field did not show any considerable change in the impedance. This method, a combined technique of anodic anodization and direct current (DC) electrodeposition, had also been used by Lin et al., who successfully synthesized nickel NWs. Using an ordered porous alumina film as a template, it is found that the Ni NWs with different diameter and coercivity exhibit high perpendicular anisotropy. Based on an approach by Masuda and Fukuda, Nielsch et al. fabricated ordered porous alumina arrays with a sharply defined pore diameter by a two-step electrochemical anodization aluminum process, and homogeneously filled $\mathrm{Ni}$ into porous alumina templates by pulsed electrodeposition. The magnetic behavior of Ni NWs of $100 \mathrm{~nm}$ period arrays were characterized by magnetometry and magnetic force microscopy and the results show that stray field interactions of single domain NWs are entirely dependent on the NW diameter.

\subsection{Ferromagnetic alloys}

\subsubsection{Fe-Ni}

Fe-Ni alloys are the most common kind of soft magnetic, which have a series of physical properties with varietal ratio of component. At an aim of superior magnetic properties such as higher coercivity and higher remanence ratio, Fe-Ni alloys NWs are prepared by a variety of components. The alloy $\mathrm{NW}$ arrays of $\mathrm{Ni}_{80} \mathrm{Fe}_{20}$ had been fabricated using electro deposition in nanoporous alumina templates. By the analysis of magnetic properties, they observed higher coercivity of $84349.5 \mathrm{~A} / \mathrm{m}$ and higher $\mathrm{Mr} / \mathrm{Ms}$ compared to a body material. Soft magnetic $\mathrm{Fe}_{26} \mathrm{Ni}_{74} \mathrm{NWs}$ of $18 \mathrm{~nm}$ diameter and various lengths, electrodeposited in the pores of anodic alumina, were synthesized by Khan et al. (Khan \& Petrikowski, 2000), who made a depth research on its properties such as the room temperature magnetization, magnetoresistance and structural properties. NWs show perpendicular magnetic anisotropy, anisotropic crystallographic and magnetoresistance behavior with a coercivity of 967 Oe and a remanence value of $85 \%$, and it should be noted that an electrodeposited $\mathrm{Fe}_{26} \mathrm{Ni}_{74}$ layer $(6 \mu \mathrm{m})$ on a copper substrate shows in-plane anisotropy and a coercivity of less than 1 Oe. It is found that the size dependence of the macro-magnetic properties is very interesting in $\mathrm{Fe}_{0.68} \mathrm{Ni}_{0.32} \mathrm{NW}$ arrays. In order to make a further study for this phenomenon, Liu et al. made an investigation on the effect of diameter on micro-magnetic properties of $\mathrm{Fe}_{0.68} \mathrm{Ni}_{0.32} \mathrm{NW}$ arrays (Liu et al., 2004). NW arrays of the alloy, $\mathrm{Fe}_{0.68} \mathrm{Ni}_{0.32}$, with different NW diameters had been fabricated by the electrochemical deposition method. XRD patterns of $\mathrm{Fe}_{0.68} \mathrm{Ni}_{0.32} \mathrm{NW}$ arrays with different diameters indicate that the $\mathrm{Fe}_{0.68} \mathrm{Ni}_{0.32} \mathrm{NWs}$ have a BCC structure with $<110>$ as the texture direction, which is parallel to the long axis of the NWs as shown in Fig 18. Mossbauer spectra are shown in Fig 19. The Mossbauer spectra of the NW arrays with smaller diameters show an absence of the second and fifth peaks, and then it emerge with increasing diameter. Hyperfine parameters extracted from the Mossbauer spectra show that the isomer shift and quadruple splitting are insensitive to 
changes in the diameter. The FWHM and hyperfine field have evident changes when the $\mathrm{NW}$ diameters increase from 16 to $100 \mathrm{~nm}$.

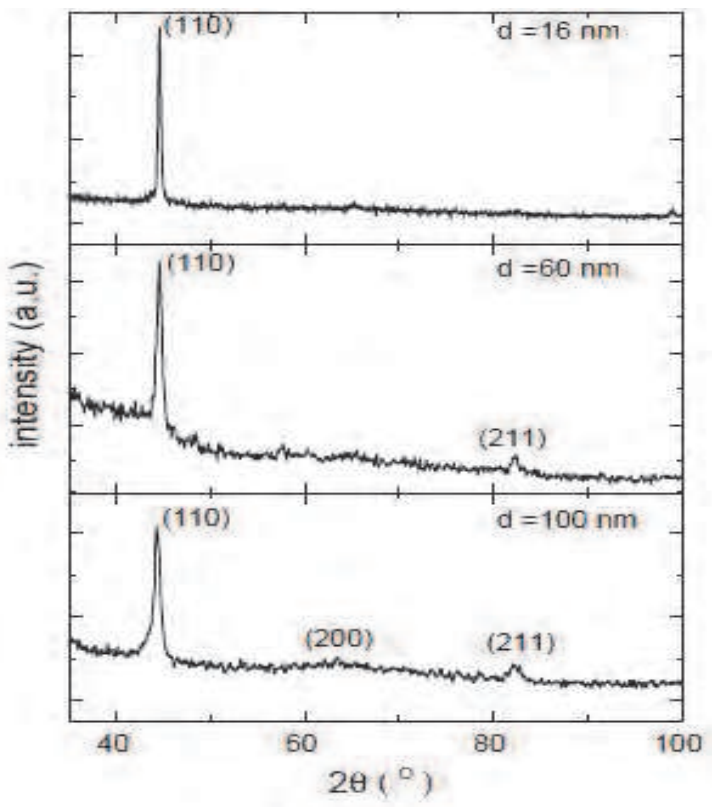

Fig. 18. XRD patterns for NW arrays of the alloy.

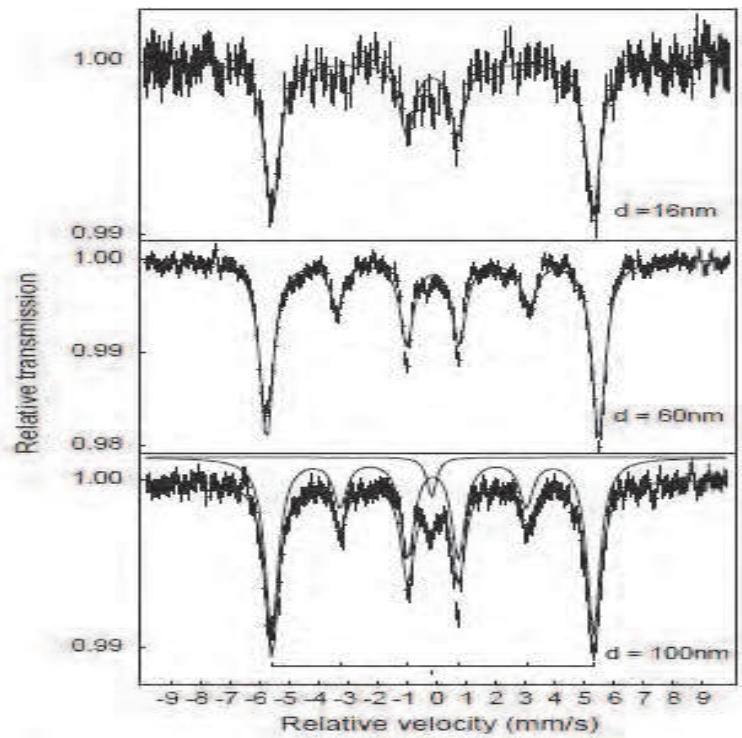

Fig. 19. M.ossbauer spectra of $\mathrm{Fe}_{0.68} \mathrm{Ni}_{0.32} \mathrm{NW}$ arrays with different diameters. 


\subsubsection{Co-Fe}

Fodor et al. had an in-depth investigation on the crystallographic and magnetic properties of various concentrations of $\mathrm{Co}_{1-x} \mathrm{Fe}_{x}$ alloys by electro-deposition in the alumina matrix produced by anodization in oxalic acid (Fodor et al., 2002). To obtain highly ordered pores a two-step anodization process was employed. Fig 20 shows that the crystalline structure of the NWs is concentration dependent and a transition from the cobalt hexagonal-closedpacked structure (hcp) to a face-centered-cubic structure (fcc) in the concentration range $0<x<0.1$. For an iron content greater than 15 at $\%$ the structure becomes body-centeredcubic (bcc. With magnetic measurements, it is suggested that the magnetic propertiescoercivities and squareness of hysteresis loops - of the CoFe alloy NWs are improved over the properties of similar nanostructures composed of pure Co and Fe.

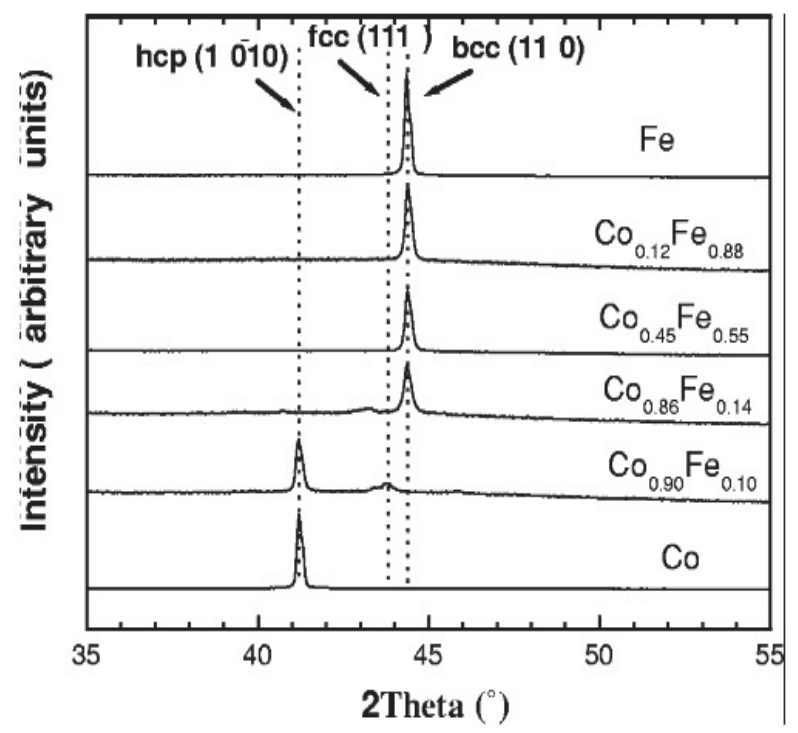

Fig. 20. X-ray diffraction pattern for $\mathrm{Co}_{1-x} \mathrm{Fe}_{x} \mathrm{NWs}$ arrays after removing the $\mathrm{Al}$ substrate.

The concentration dependence of the coercivity force along the NW axis appears to be related to the crystalline structure of the NWs and the coercivity reaches a maximum in the range in which the NWs crystallize in the body-centered-cubic structure. Khan et al. designed an experiment to fabricate the arrays of Co and $\mathrm{Co}_{90} \mathrm{Fe}_{10} \mathrm{NWs}$ (of diameters 18 and $78 \mathrm{~nm}$ ) by electrochemical method (Khan \& Petrikowski, 2002). They had investigated the structural and magnetic properties of the isolated, electrodeposited Co and Co Fe NWs of 18 and $78 \mathrm{~nm}$ diameters. The arrays of $18 \mathrm{~nm}$ diameter show perpendicular magnetic anisotropy, and $\mathrm{Co}_{90} \mathrm{Fe}_{10}$ shows enhanced $\mathrm{Hc}(\perp)$ and $\mathrm{Mr}(\perp)$ values compared to Co. The perpendicular magnetic anisotropy and the values of $\mathrm{Hc}(\perp)$ and $\operatorname{Mr}(\perp)$ decrease with increasing NW diameter and interwire distance.

\subsubsection{Co-Ni}

As a soft magnetic material, Co-Ni alloys can be used as magnetic recording materials, and their magnetic properties can be greatly improved by changing components or adding other 
trace elements. However, magnetic properties of the Co-Ni alloys film, which has a lot of research, are difficult to satisfy the condition of highly density perpendicular magnetic recording because of its small Hysteresis loop squareness ratio. Co-Ni NWs alloys are expected to exhibit a high degree of magnetic anisotropy and a higher hysteresis loop squareness ratio. Co-Ni NW arrays have been successfully fabricated by ac electro-deposition in porous anodic aluminum oxide template and have been studied for the relationship between magnetic properties and $\mathrm{Co}-\mathrm{Ni}$ components. The result of magnetic measurement suggests that squareness ratio and coercivity of Co-Ni NW arrays can be modulated by changing the component of Co-Ni alloys. This kind of array film may become a promising high-density perpendicular magnetic recording material, because the Coercivity and hysteresis loop squareness of Co-Ni NW arrays are higher than that of Two-dimensional alloy film. Using AC electro-deposition, ultra small Co-Ni NWs with $8 \mathrm{~nm}$ diameters had been successfully fabricated by Zhang et al within nanochannel alumina templates (Zhang et al., 2004). The NWs possess an FCC structure and the corresponding SAED patterns showing that the NW possesses an FCC structure with the axis of the NW orientated along the $\left[\begin{array}{lll}1 & 1 & 0\end{array}\right]$ direction. The hysteresis loops of the samples with the external field perpendicular $(\perp)$ and parallel (II) to the sample plane from 5 to $350 \mathrm{~K}$ are measured. The magnetic behavior of the NWs shows strong temperature dependence. The coercivities increase greatly with the decrease in temperature. A coercivity as high as 2529 Oe has been obtained at $5 \mathrm{~K}$.

\subsection{Heterogeneous ferromagnetic-nonmagnetic alloys}

Since the magnetic properties of NW arrays are related to their element components and morphology, heterogeneous ferromagnetic-nonmagnetic alloy NW arrays systems are expected to exhibit better magnetic. The technique of electro-deposition in the pores of aluminium oxide membranes with quoted pore diameter $20 \mathrm{~nm}$ and length $60 \mu \mathrm{m}$ had been used to prepare $\mathrm{AgCo}$ and $\mathrm{AgCoCu}$ inhomogeneous alloy NWs by Fedosyuk et al (Fedosyuk et al., 1999). They had shown for the first time that it is possible to electrodeposit alloy NWs in which Ag is the predominant non-magnetic component, and that these NWs exhibit GMR. When $\mathrm{Ag}_{45} \mathrm{Co}_{25} \mathrm{Cu}_{30} \mathrm{NWs}$ were annealed, the GMR increased significantly. Schwarzacher's group had studied the Co-Cu alloy NWs (Blythe et al., 2000) and $\mathrm{Co}-\mathrm{Ni}-\mathrm{Cu} / \mathrm{Cu}$ multilayered NWs (Evans et al., 2000) electro-deposited into commercial anodic membranes. A gold layer had been evaporated on one side of the membrane to serve as a conducting electrode. The thickness or composition was controlled by the applied reduction potential. They found a large value of the current perpendicular to plane giant magnetoresistance (CPP-GMR) for $\mathrm{Co}-\mathrm{Ni}-\mathrm{Cu} \quad(5.4 \mathrm{~nm}) / \mathrm{Cu} \quad(2.1 \mathrm{~nm})$ multilayered NWs: $55 \%$ at room temperature and $115 \%$ at $77 \mathrm{~K}$.

It is difficult to use the conventional dc reduction method to produce multi-layers or alloys of two metals with large different reduction potentials, such as $\mathrm{Co}$ and $\mathrm{Cu}$ or Fe and Pt. The new method of an alternating current between the alumina template and the suitable counterelectrode has been employed. Zheng et al. had succeeded in fabricating $\mathrm{Fe} / \mathrm{Pt}$ multilayered NW arrays by alternating the alumite template between two chemical cells containing Fe and Pt ions using alternating current at a voltage of $20 \mathrm{~V}$ and a frequency of $250 \mathrm{~Hz}$ (Zheng et al., 2000). The thickness of individual layers is around $10 \mathrm{~nm}$. They found that the multilayered $\mathrm{Fe} / \mathrm{Pt} \mathrm{NWs}$ exhibit an easy magnetization along the wire axis, which is probably due to shape anisotropy. Annealing studies led to either two phase or soft-phase phenomena. Future work will be aimed at studies as a function of layer thicknesses and at achieving higher coercivity and higher anisotropy. 
Wang et al. had successfully fabricated ordered ferromagnetic-nonmagnetic alloy (Co-Cu, $\mathrm{Co}-\mathrm{Ag}$, and Fe-Ag) NW arrays embedded in the nanochannels of AAM by electrodeposition and studied their annealing temperature dependence of magnetic properties in detail (Wang et al., 2002). SEM and TEM observations reveal that those alloy NWs are uniform in diameter and ordered. Magnetic measurements show that the perpendicular coercivity $\left(\mathrm{HC}^{\perp}\right)$ of those ordered NW arrays embedded in AAM increases dramatically as annealing temperature (TA) rises, reaches their maximum at one temperature, and then decreases sharply as TA rises further. However, there is not much change of the parallel coercivity $\left(\mathrm{HC}^{\|}\right)$for these alloy NW arrays in the same annealing conditions.

Yuan et al. fabricated perpendicular anisotropy ternary magnetic NW arrays for ultra-highdensity magnetic recording. They fabricated Ni-W-P alloy NW arrays by electroless deposition in an anodic alumina membrane. The magnetic properties of Ni-W-P alloy NW arrays were characterized using a vibrating sample magnetometer. The hysteresis loops show that the easily magnetized direction of Ni-W-P NW arrays is parallel to the NW arrays and that it has obvious magnetic anisotropy as a result of the shape anisotropy. So we can see that electroless deposition opens up significant opportunities in the nanoscale fabrication of magnetic materials for ultra-high-density magnetic recoding. In addition, our research group studied different magnetic nanowires (Zhou et al., 2008; Zhou et al., 2008; Lu et al., 2010; Zhou et al., 2010; Zhou et al., 2011).

\section{Concluding remarks}

As we all know, thermoelectric (Zhou et al., 2011; Yang et al., 2009; Etessam-Yazdani et al., 2009; Sait \& Ma, 2009; Narayanan et al., 2009; Hopkins \& Beechem, 2010; Heatwole et al., 2009; Youssef \& Elsibai, 2011) and magnetic (Zhou et al., 2011; Zhou et al., 2008; Zhou et al., 2008; Lu et al., 2010; Zhou et al., 2010; Zhou et al., 2011) materials have a very attractive prospect because of their special performance. Theory predicts that the properties of the thermoelectric and magnetic NWs may have a higher improvement compared to their bulk structure. In the earlier sections, we have discussed the synthetic strategies and properties of various thermoelectric and magnetic NWs, and the results of the experiment are generally agreement with the theoretical predictions. Clearly, there has been intense activity in this area demonstrating considerable success in preparing NWs in good quantities with a reasonable control on the dimensions. In order to improve the thermoelectric or magnetic properties of materials, there is little doubt that thermoelectric and magnetic NWs will be prepared in the future. New strategies will also be developed for the synthesis and manufacture of these materials.

\section{Acknowledgments}

This work was partially supported by the Program for Science \& Technology Innovation Talents in Universities of Henan Province (No.2008 HASTIT002), Innovation Scientists and Technicians Troop Binstruction Projects of Henan Province (No.094100510015), and by the Natural Science Foundation of China under Grant No. 20971036.

\section{References}

Aimawlawi, D.; Coombs, N. \& Moskovits, M. (1991). J. Appl. Phys., Vol. 70, P. 4421

Aranda, P. \& Garcia,M. J. (2002). Magn. Mater., Vol. 249, P. 214 
Bejenari, I.; Kantser, V. \& Balandin, A. (2010). Phys. Rev. B., Vol. 81, P. 075316

Bell, L. E.; (2008). Science Vol. 321, P. 1457

Blythe, H.; Fedosyuk, V.; Kasyutich, O. \& Schwarzacher, W. (2000). J. Magn. Magn. Mater., Vol. 208, P. 251

Bucherer, A.H.; (1900). Ann. Physik, Vol. 3, P. 204

Chaure, N.; Stamenov, P.; Rhen, F. \& Coey, J. (2005). J. Magn. Magn. Mater., Vol. 290, P. 1210

Dong, A.; Wang, F.; Daulton, T. \& Buhro, W. (2007). Nano Lett., Vol. 7, P. 1308

Dresselhaus, M.; Lin, Y.; Rabin, O.; Jorio, A.; Souza Filho, A.; Pimenta, M.; Saito, R.; Samsonidze, G. \& Dresselhaus,G. (2003). J. Mater. Sci. Eng. C, Vol. 23, P. 129

Etessam-Yazdani, K.; Asheghi, M. \& Hamann, H. (2009). Nanosc. Microsc. Therm., Vol. 13, P. 203

Evans, P. R.; Yi, G. \& Schwarzacher, W. (2000). Appl. Phys. Lett., Vol. 76, P. 481

Fedosyuk, V.; Kasyutich, O. \& Schwarzacher, W. (1999). J. Magn. Magn. Mater., Vol. 198, P. 247

Fodor, P.; Tsoi, G. \& Wenger, L. (2002). J. Appl. Phys., Vol. 91, P. 10

Gao, Y.; Niu, H.; Zeng, C. \& Chen, Q. (2003). Chem. Phys. Lett., Vol. 367, P. 141

Givargizov, E. (1975). J. Crystal Growth, Vol. 31, P. 20

Gudiksen, M. S. \& Lieber, C. M. (2000). J. Am. Chem. Soc., Vol. 122, P. 8801

Heremans, J.; Thrush, C.; Lin, Y.; Cronin, S.; Zhang, Z.; Dresselhaus, M. \& Mansfield, J. (2000). Phys. Rev. B., Vol. 61, P. 2921

Heatwole, S.; Veeraragavan, A.; Cadou, C. \& Buckley, S. (2009). Nanosc. Microsc. Therm., Vol. 13, P. 54

Hochbaum, A.; Chen, R.; Delgado, R.; Liang, W. \& Yang, P. (2008). Nature, Vol. 451, P. 408

Hopkins, P. \& Beechem, T. (2010). Nanosc. Microsc. Therm., Vol. 14, P. 51

Huysmans, G. \& Lodder, J. (1988). J. Appl. Phys., Vol. 64, P. 2016

Jin, C.; Xiang, X.; Jia, C.; Liu, W.; Cai, W.; Yao, L. \& Li, X. (2004). J. Phys. Chem. B., Vol. 108, P. 1844

Ju, Y. \& Goodson, K. (1999). Appl. Phys. Lett., Vol. 74, P. 3005

Kazadi Mukenga Bantua, A.; Rivas, J.; Zaragoza, G.; López-Quintela, M. \& Blanco, M. (2001). J. Appl. Phys., Vol. 89, P. 615

Khan, H. \& Petrikowski, K. (2000). J. Magn. Magn. Mater., Vol. 215, P. 528

Khan, H. \& Petrikowski, K. (2002). Mater. Sci. and Eng. C., Vol. 19 P. 345

Lecher, E. (1905). Physikal. Zeitschr., Vol. 6, P.781

Lee, W.; Ji, R.; Gosele, U. \& Nielsch, K. (2006). Nat. Mater., Vol. 5, P. 741

Li, A.; Muller, F.; Birner, A.; Nielsch, K. \& Gosele, U. (1998). J. Appl. Lett., Vol. 84, P. 6023

Li, D. (2003). Appl. Phys. Lett., Vol. 83, P. 15

Li, D.; Wu, Y.; Kim, P.; Shi, L. \& Yang, P. (2003). Appl. Phys. Lett., Vol. 83, P. 2934

Li, F. \& Metzger, R. (1997). J. Appl. Phys., Vol. 81, P. 3806

Li, F.; Zhang, L. \& Metzger, R. (1998). Chem. Mater., Vol. 10, P. 2470

Li, L.; Yang, Y.; Huang, X.; Li, G. \& Zhang, L. (2006). Nanotechnology, Vol. 17, P. 1706

Lin, Y. \& Dresselhaus, M. (2003). Phys. Rev. B, Vol. 68, P. 075

Ling, A.; Muller, F.; Birner, A.; Nielsch, K. \& Gosele, U. (1999). Adv. Mater. Vol. 11, P. 483

Liu, J.; Yu, M. \& Li, S. (2005). Chin. J. Inorg. Chem. Vol. 21, P. 429

Liu, K.; Chien, C.; Searson, P. \& Y. Kui. (1998). Appl. Phys. Lett., Vol. 73, P. 1436

Liu , Q.; Wang, J.; Yan, Z. \& Xuel, D. (2004). J. Magn. Magn. Mater., Vol. 278, P. 323

Lu, M. \& Zhou, S. (2010). Phys. Lett. A, Vol. 372, P. 2300

Mahan, G.; Sales, B. \& Sharp, J. (1997). Phys. Today., Vol. 50, P. 42

Martin-Gonzalez, M.; Prieto, A.; Gronsky, R.; Sands, T. \& Stacy, A. (2003). Adv. Mater., Vol. 15, P. 1003

Masuda, H.; Hasegwa, F. \& Ono, S. (1997). J. Electrochem. Soc., Vol. 144, P. 127 
Menon, L.; Zheng, M.; Zeng, H.; Bandyopadhyay, S. \& Sellmyer, D. (2000). J. Electron. Mater., Vol. 29, P.510

Miyazaki, Y. \& Kajitani, T. (2001). J. Crystal Growth, Vol. 229, P. 542

Narayanan, S.; Fedorov, A. G. \& Joshi, Y. (2009). Nanosc. Microsc. Therm., Vol. 13, P. 30

Otten, C.; Lourie, O. \& Yu, M. (2002). J. Am. Chem. Soc. Vol. 124, P. 4564

Piraux, L.; Dubois, S.; Duvail, J.; Radulescu, A.; Demoustier-Champagne, S.; Ferain, E. \& Legras, R. (1999). J. Mater. Res., Vol. 14, P. 3042

Prieto. A. (2003). J. Am. Chem. Soc., Vol. 125, P. 2388

Prieto, A.; Martin-Gonzalez, M.; Keyani, J.; Sands, T. \& Stacy, (2003). A. J. Am. Chem. Soc., Vol. 125, P. 2388

Prieto, A.; Sander, M.; Martin-Gonzalez, M.; Gronsky, R.; Sands, T. \& Stacy, A. (2001). J. Am. Chem. Soc., Vol. 123, P. 7160

Qin, R. (2006). Chin. J. Micrnanoelectr. Techn. (Chinese), Vol. 43, P. 372

Venkatasubramanian, R.; Siivola, E. \& Colpitts, T. (2001). Nature, Vol. 413, P. 597

Thompson, R.J. (1932). Ind. Eng. Chem. Vol. 24, P. 620

Wagner, R. S. \& Ellis, W. C. (1964). Appl. Phys. Lett., Vol. 4, P. 89

Wang, W.; Qu, J.; Lu, X.; Zhang, G.; Li, G. \& Li, X. (2007). Mater. Sci. Forum., Vol. 546, P. 2171

Wang, Y.; Zhang, L.; Meng, G.; Peng, X.; Jin, Y. \& Zhang, J. (2002). J. Phys. Chem. B., Vol. 106, P. 2502

Weber, L. \& Gmelin, E. (1991). Appl. Phys. A, Vol. 53, P. 136

Wu, Y.; Fan, R. \& Yang, P. (2002). Nano Lett., Vol. 2, P. 283

Wu, Y.; Yan, H.; Huang, M.; Messer, B.; Song, J. \& Yang, P. (2002). Chem.-Eur. J., Vol. 8, P.1261

Wu, Y. \& Yang, P. (2001). J. Am. Chem. Soc., Vol. 123, P. 3165

Xue, F.; Fei, G.; Wu, B.; Cui, P. \& Zhang, L. (2005). J. Am. Chem. Soc., Vol. 127, P. 15348

Yang, Y.; Hamann, H. \& Asheghi, M. (2009). Nanosc. Microsc. Therm., Vol. 13, P. 88

Yoo, B.; Xiao, F.; Bozhilov, K.; Herman, J.; Ryan, M. \& Myung, N. (2007). Adv. Mater., Vol. 19, P. 296

Youssef, H. \& Elsibai, K. (2011). Nanosc. Microsc. Therm., Vol. 15, P. 48

Zhang, X.; Xu, L.; Dai, J. \& Chan, H. (2004). Phys. B., Vol, 353, P. 187

Zhang, Z.; Gekhtman, D.; Dresselhaus, M. \& Ying, J. (1999). Chem. Mater., Vol. 11, P. 1659

Zhang, Z.; Sun, X.; Dresselhaus, M.; Ying, J. \& Heremans, J. (1998). Appl. Phys. Lett., Vol. 73, P. 1589

Zhang, Z.; Sun, X.; Dresselhaus, M.; Ying, J. \& Heremans, J. (2000). Phys. Rev. B, Vol. 61, P. 4850

Zeng, H.; Zheng, M.; Skomski, R.; Sellmyer, D.; Liu, Y.; Menon, L. \& Bandyopadhyay, S. (2000). J. Appl. Phys., Vol. 87, P. 4718

Zheng, M.; Liu, Y.; Zeng, H.; Bandyopadhyay, S.; Kirby, R. \& Sellmyer, D. (2000). APS March Meeting

Zhou, J.; Jin, C.; Seol, J. \& Shi, L. (2005). Appl. Phys. Lett., Vol. 87, P.133109

Zhou, S.; Li, N.; Wang,Y.; Lou, S.; Chen, X.; Yuan, H.; Liu, L. \& Wang, P. (2011). Nanosc. Microsc. Therm., Vol. 15, P. $x$

Zhou, S.; Liu, L.; Lou, S.; Wang, Y.; Chen, X.; Yuan, H.; Hao, Y.; Yuan, R. \& Li, N. (2011). Appl. Phys. A, Vol. 102, P. 367

Zhou, S.; Lou, S.; Wang, Y.; Chen, X.; Liu, L. \& Yuan, H. (2011). Nanoscale Res. Lett., Vol. 6, P. 285.

Zhou, S.; Wang, P.; Li, S.; Zhang, B.; Gong, H. \& Du, Z. (2008). Chin. Phys. Lett., Vol. 25, P. 4446

Zhou, S.; Yuan, H.; Liu, L.; Chen, X.; Lou, S.; Hao, Y.; Yuan, R. \& Li, N. (2010). Nanoscale Res. Lett., Vol. 5, P. 1284

Zhou, S.; Zhang, X.; Gong, H.; Zhang, B.; Wu, Z.; Du, Z. \& Wu, S. (2008). J. Phys.: Condens. Matter, Vol. 20, P. 075217 


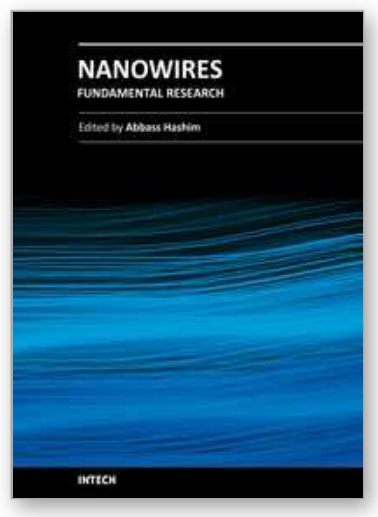

\author{
Nanowires - Fundamental Research \\ Edited by Dr. Abbass Hashim
}

ISBN 978-953-307-327-9

Hard cover, 552 pages

Publisher InTech

Published online 19, July, 2011

Published in print edition July, 2011

Understanding and building up the foundation of nanowire concept is a high requirement and a bridge to new technologies. Any attempt in such direction is considered as one step forward in the challenge of advanced nanotechnology. In the last few years, InTech scientific publisher has been taking the initiative of helping worldwide scientists to share and improve the methods and the nanowire technology. This book is one of InTechâ $€^{\mathrm{TM}_{\mathrm{S}}}$ attempts to contribute to the promotion of this technology.

\title{
How to reference
}

In order to correctly reference this scholarly work, feel free to copy and paste the following:

Yu-Biao Liu and Shao-Min Zhou (2011). Thermoelectric and Magnetic Nanowires, Nanowires - Fundamental Research, Dr. Abbass Hashim (Ed.), ISBN: 978-953-307-327-9, InTech, Available from:

http://www.intechopen.com/books/nanowires-fundamental-research/thermoelectric-and-magnetic-nanowires

\section{INTECH}

open science | open minds

\author{
InTech Europe \\ University Campus STeP Ri \\ Slavka Krautzeka 83/A \\ 51000 Rijeka, Croatia \\ Phone: +385 (51) 770447 \\ Fax: +385 (51) 686166 \\ www.intechopen.com
}

\author{
InTech China \\ Unit 405, Office Block, Hotel Equatorial Shanghai \\ No.65, Yan An Road (West), Shanghai, 200040, China \\ 中国上海市延安西路65号上海国际贵都大饭店办公楼405单元 \\ Phone: +86-21-62489820 \\ Fax: $+86-21-62489821$
}


(C) 2011 The Author(s). Licensee IntechOpen. This chapter is distributed under the terms of the Creative Commons Attribution-NonCommercialShareAlike-3.0 License, which permits use, distribution and reproduction for non-commercial purposes, provided the original is properly cited and derivative works building on this content are distributed under the same license. 